\title{
Epidemiology and pattern of paediatric injuries in a developing country: an analysis of 170 injuries
}

\author{
Ndubuisi O. Onyemaechi ${ }^{1}$, Adaobi I. Bisi-Onyemaechi ${ }^{2}$, Obinna C. Nduagubam ${ }^{3}$ \\ 1. Department of Surgery, College of Medicine, University of Nigeria Ituku-Ozalla Enugu, Nigeria \\ 2. Department of Paediatrics, College of Medicine, University of Nigeria Ituku-Ozalla Enugu, Nigeria \\ 3. Department of Paediatrics, Enugu State University College of Medicine (ESUCOM), Enugu Nigeria
}

Correspondnce: Ndubuisi O. Onyemaechi; ndubuisi.onyemaechi@unn.edu.ng

\section{Background}

\section{Abstract}

Paediatric injuries have significant physical, psychological and socioeconomic consequences. This study aimed to determine the epidemiology and pattern of paediatric injuries presenting at a teaching hospital in Enugu South-East Nigeria.

Methods

A retrospective study of injured patients less than 18 years who presented to the Accident and Emergency department of University of Nigeria Teaching Hospital Ituku/Ozalla, in Enugu Nigeria, was conducted from 1st January to 31st December 2015. Analysis of data was done using Statistical Package for the Social Sciences version 22.0.

Results

A total of 1191 children presented to the hospital within the study period and 120 injured paediatric patients (10.1\%) with 170 injuries were attended to in the A \& E. Adolescents (12-17 years) accounted for $34.2 \%$ of injuries and males $(70 \%)$ were more affected than the females. Road traffic crashes and falls were the most common causes of paediatric injuries. There was a significant correlation between age of the children and the aetiology of the injuries $(X 2=28.08, p=0.001)$. Bruises/lacerations/abrasions $(27.6 \%)$ and fractures $(27.1 \%)$ were the most common types of injuries sustained. The injury severity score (ISS) of the patients ranged from 1-25 with a mean of $6.4+2.8$. Roadside/street (35\%), school $(23.3 \%)$ and home $(21.7 \%)$ were the main locations where injuries occurred. Mean injury-arrival interval was $1.2+0.7$ days. Majority $(67.5 \%)$ of children had full recovery and the mortality rate was $5.8 \%$.

Conclusions

Road traffic crashes and falls were the most common cause of paediatric injuries. Soft tissue trauma and fractures were the predominant types of injuries. Roadside, school and home were the leading locations of childhood injuries. Prevention of road traffic crashes and falls, prompt treatment of injuries, and rehabilitation of injured children will reduce the negative impact of paediatric injuries.

\section{Keywords: Injuries; Children; Pattern; Epidemiology; Prevention}

\section{Introduction}

Trauma is the leading cause of morbidity and mortality among persons less than 40 years and the third commonest cause of death among all ages globally ${ }^{1,2}$. Paediatric injuries have become a global public health problem as they are associated with significant morbidity and mortality. Each year, 10-30 million children and adolescents sustain injuries and approximately one million children die every year due to accidental injuries or violence worldwide ${ }^{3}$. In developing countries with a huge burden of communicable and nutritional diseases, paediatric injuries have been estimated to account for $13 \%$ of childhood disease burden ${ }^{4}$. However, with increasing urbanization, motorized transportation and armed ethno-religious conflicts, trauma is displacing malnutrition and communicable diseases as a major cause of childhood morbidity and mortality in developing countries ${ }^{5,6}$. According to a world report on child injury prevention in 2008 , it was projected that childhood injury and violence will be a predominant killer of children by the year 2020 globally $y^{5}$.

The causes and pattern of paediatric injuries have been reported to be influenced by age, gender, socio-economic and environmental factors ${ }^{7}$. Children sustain injuries from a number of causes including road traffic crashes (RTCs), falls from heights in playground and at home, burns as well as during birth. Several studies report that land transport-related injuries continue to dominate among the various causes of injuries in children in both developed and developing countries $^{5,8-11}$. Falls and injuries from playground equipment are other important causes of childhood injuries ${ }^{12}$. The formulation and enforcement of deliberate policies towards improving child safety particularly on the roads/streets, schools and homes which has remained a challenge in most low and middle-income countries has further compounded the problem ${ }^{8,13}$. The World Health Organization (WHO) and United Nations International Children's Emergency Fund (UNICEF) are scaling up their strategies in the area of child and adolescent injury prevention and have advocated global attention to reduce childhood injuries using a range of strategies, including playground safety and safeguards against injury ${ }^{14}$.

Childhood injuries are common causes of hospitalization and are often associated with huge financial costs and may require prolonged hospital stay resulting in economic losses and psychological disturbances. Several factors expose children to high risk of trauma and its consequences. These range from the lack of safe playing grounds, overcrowded homes, children's poor judgment of safety, poor supervision by care-givers, outright carelessness, maternal depression and alcohol/drug abuse to non-observance of home safety measures ${ }^{5,15}$. In our local setting, the unregulated and unprotected use of motorcycles as a common means of transportation has further increased the burden of childhood injuries ${ }^{16}$. There is paucity of data on the epidemiology of paediatric injuries in Nigeria and other developing countries. Most published studies either focused on specific injuries or on injuries resulting from a particular aetiologic factor. Epidemiological studies help to determine the causes, 
patterns, severity and the impact of injuries on the overall child health in a setting. The information from such studies will also help in organizing priorities for improving paediatric trauma care and the overall child health. Most causes of paediatric injuries are preventable and a good understanding of the epidemiology and pattern is critical in formulating prevention strategies and treatment protocols. In view of these challenges and to reference the past in managing the present and future events, study was then designed to identify the aetiological factors, characteristics and outcome of paediatric injuries in this part of the globe hoping to suggest preventive strategies and treatment protocols for childhood injuries in low and middle-income countries which are still developing like Nigeria.

\section{Methods}

We conducted a retrospective study of injured patients less than 18 years who presented to the accident and emergency (A\&E) unit of University of Nigeria Teaching Hospital (UNTH) Ituku-Ozalla, in Enugu Nigeria, from $1^{\text {st }}$ January to 31st December 2015. The UNTH is the largest referral hospital in Southeast Nigeria with a 500-bed capacity located along the Enugu-Port-Harcourt expressway about $27 \mathrm{~km}$ from the city of Enugu. The tertiary healthcare centre provides comprehensive trauma care to the residents of Enugu State and neighbouring states of Southeast, Southsouth and Northcentral Nigeria. It serves a population of about 8 million people. Injured patients are first seen at the A \& E department and the treatment protocol is according to the advanced trauma life support (ATLS) principles. Patients are either discharged from the A \& E department or admitted to the paediatric surgical/neurosurgical ward or, intensive care unit (ICU) depending on the type/pattern and severity of the injuries. Ethical approval to conduct the study was obtained from the Research and Ethics Committee of University of Nigeria Teaching Hospital Ituku-Ozalla before the commencement of the study.

All the children less than 18 years of age who sustained injuries and presented to the $\mathrm{A} \& \mathrm{E}$ department of the hospital from $1^{\text {st }}$ January to $31^{\text {st }}$ December 2015 were studied retrospectively. The medical records of the patients were reviewed. Socio-demographic profile of the patients, aetiology and circumstance of the injury, injury-arrival interval, type of injury, injury severity score, duration of hospitalization and outcome of treatment were extracted from the case files. Patients were followed up by the attending surgical team at regular intervals for at least one year. During the followup period, the outcome of the treatment and presence of any complications were evaluated. Data were extracted and entered into a proforma designed for the study based on information from learned referenced journals. Patients with incomplete records were excluded from the study. The severity of injuries was determined by the Injury Severity Score (ISS). Injury severity was categorized as mild if the ISS was less than 9; moderate if the ISS was 9-15; severe if ISS was 16-24 and profound if ISS was 25 or greater ${ }^{17}$. Patients with traumatic brain injury (TBI) were classified using the Paediatric Glasgow Coma Scale (PGCS) for children less than 2 years; and Glasgow Coma Scale (GCS) for children older than 2 years. A GCS of 3-8 was described as severe, 9-12 was moderate while 13-15 was mild head injury. Analysis of data was done using Statistical Package for the Social Sciences (SPSS) version 22.0 (IBM Corp, Armonk, NY USA). The

Table 1: Age distribution of the Patients

\begin{tabular}{lccc} 
Age group & Male & Female & No (\%) \\
$1-28$ days (Neonates) & 4 & 3 & $7(5.8)$ \\
$1-12$ months (Infants) & 3 & 2 & $5(4.2)$ \\
$1-3$ years (Toddlers) & 9 & 6 & $15(12.5)$ \\
$4-5$ years (Pre-school) & 16 & 8 & $24(20.0)$ \\
$6-11$ years (School age) & 23 & 5 & $28(23.3)$ \\
$12-17$ years (Adolescents) & 29 & 12 & $41(34.2)$ \\
Total & $84(70 \%)$ & $36(30 \%)$ & $120(100 \%)$ \\
\hline
\end{tabular}

Table 2: Distribution of the etiology of injuries by age

\section{Etiology of Injuries}

\begin{tabular}{|c|c|c|c|c|c|c|c|c|c|}
\hline Age & RTA & Fall & Gunshot & Burns & Sports injury & $\begin{array}{l}\text { Industrial } \\
\text { injury }\end{array}$ & Child abuse & Birth Injury & Total \\
\hline $1-28$ days & - & - & - & - & - & - & - & 7 & 7 \\
\hline $1-12$ months & 3 & 2 & - & - & - & - & - & - & 5 \\
\hline $1-3$ years & 5 & 6 & - & 4 & - & - & - & - & 15 \\
\hline $4-5$ years & 8 & 12 & - & 2 & 2 & - & - & - & 24 \\
\hline $6-11$ years & 11 & 8 & - & - & 6 & - & 3 & - & 28 \\
\hline $11-17$ years & 13 & 5 & 2 & 2 & 6 & 3 & 10 & - & 41 \\
\hline Total & $40(33.3 \%)$ & $33(27.5 \%)$ & $2(1.7 \%)$ & $8(6.7 \%)$ & $14(11.7 \%)$ & $3(2.5 \%)$ & $13(10.8 \%)$ & $7(5.8 \%)$ & $\begin{array}{l}120 \\
(100 \%)\end{array}$ \\
\hline
\end{tabular}


frequencies of variables were identified using descriptive statistics. Chi-square test was used to determine association between categorical variables. Test of relationships was done using Pearson's correlation analysis. Statistical significance was set at $\mathrm{p}$-value $<0.05$. Multivariate regression analysis was used to determine the causal relationships among variables.

\section{Result}

\section{Patients' characteristics}

A total of 120 patients with injuries were studied. During the study period, 1191 children with both medical and surgical conditions were admitted. This gives a paediatric injury prevalence of $10.1 \%$. The age of the patients ranged from 2 days to 17 years with a mean age of $8.3 \pm 3.6$ years. Adolescents accounted for 41 (34.2\%), while school age and pre-school age children were $28(23.3 \%)$ and $24(20 \%)$ respectively (Table 1). Eighty-four $(70 \%)$ patients were male and $36(30 \%)$ were female children giving a male: female ratio of 2:1

\section{Circumstances of injury}

A total of $13(10.8 \%)$ patients were injured by child abuse (intentional injuries) while 107 (89.2\%) children sustained unintentional injuries. Out of the 13 patients with intentional injuries, 9 were physically abused while 4 were sexually assaulted. Most of the patients injured by child abuse were older children (Table 2). However, certain injuries in the younger children prompted investigation into non-accidental trauma but were unconfirmed. Road traffic crash was the commonest cause of paediatric injuries accounting for (40; $33.3 \%$ ) of all the injuries with in the study period, followed by falls from height $(33 ; 27.5 \%)$. Gunshot was the least common cause of injuries in our study (Table 2). Seven neonates presented with birth injuries. Five of them were delivered in hospital, while 2 were delivered by traditional birth attendants. All the patients had a history of difficult vaginal delivery. Among the patients who sustained road traffic injuries (RTIs), 15 were pedestrian injuries, 10 were from motor vehicular accidents, 9 were from motorcycle accidents while 6 involved tricycles. There was a positive correlation between the age of the patients and the etiology of the injuries $\left(\mathrm{X}^{2}=28.08 ; \mathrm{p}=0.001\right)$. The older children mostly sustained injuries from road traffic crashes, sports and child abuse. The pre-school age children were more prone to falls while playing at home (Table 2). Most of the falls (20; $60.6 \%)$ occurred while playing, $11(33.3 \%)$ were falls from trees while $2(6.1 \%)$ occurred on stairs. Majority (42; 35\%) of the injuries in children occurred by the roadside or along the street. This was followed by injuries at school and at home (Table 3). Home injuries occurred mostly among pre-school age children while roadside, school and playground injuries occurred mostly among the older children $\left(\mathrm{X}^{2}=16.20 ; \mathrm{p}=\right.$ 0.012). The injury-arrival interval ranged from 25 minutes to 15 days with a mean of $1.2 \pm 0.7$ days. Only $7(5.8 \%)$ patients presented within the first one hour of the injury (golden hour). Twenty-seven $(22.5 \%)$ presented within 2-6 hours of injury, $28(23.3 \%)$ presented 7-24 hours, 45 (37.5\%) patients came within 1-7 days while $13(10.8 \%)$ presented after one week.

\section{Injury characteristics}

A total of 170 injuries were recorded. Approximately onethird of the patients sustained multiple injuries $(37 ; 30.8 \%)$. Soft tissue injuries (bruises, lacerations and abrasions) and fractures were the commonest types of injuries sustained (Table 4). Children injured by child abuse mostly sustained abrasions, bruises and lacerations. The lower extremities were the most commonly injured body region. Other body regions affected by injuries are shown in Table 5. Two teenagers sustained perineal bruises from sexual abuse while one child sustained shoulder dislocation from physical abuse. Out of the seven neonates with birth injuries, 5 sustained clavicular fractures, while the remaining 2 sustained humeral and femoral shaft fractures respectively. Analysis of the injury characteristics showed that traumatic brain injuries (TBI) resulted mostly from RTCs and falls $\left(\mathrm{X}^{2}=13.96\right.$; $\mathrm{p}$ $=0.024)$. The distribution of the severity of TBI was as follows: severe $=10$; moderate $=8$ and mild $=5$. Most of the fractures were closed $(36 ; 78.3 \%)$, while $10(21.7 \%)$ were open fractures. The sites of the fractures recorded were as follows: supracondylar humerus $=10$; radius $/$ ulna $=8$; tibia/ fibula $=12$; femoral shaft $=6$; humeral shaft $=3$; clavicle $=$ 5 ; pelvis $=2$. There were seven joint dislocations, 4 occurred in the elbow while 3 were shoulder dislocations. Out of the 7 spine injuries, 4 were complete while 3 were incomplete injuries. Four of the spine injuries occurred in the cervical spine, 2 occurred in the thoracic spine, while 1 occurred in the lumbar spine. Majority of the burn injuries involved the lower limbs and the trunk and resulted from scalds $(6 ; 60 \%)$ and flame burns $(4 ; 40 \%)$. There was no chemical, electrical or radiation burns. The percentage of the total body surface area (\% TBSA) ranged from $4 \%-45 \%$ with a median of $10 \%$. The injury severity score (ISS) of the patients ranged from $1-25$ with a mean ISS of $6.4 \pm 2.8$. Majority of the patients $(75 ; 62.7 \%)$ sustained minor injuries, $34(28.2 \%)$ sustained moderate injuries while $11(9.1 \%)$ sustained severe injuries. Severe injuries were associated with early presentation to hospital and prolonged hospital stay $\left(\mathrm{X}^{2}=25.62 ; \mathrm{p}=0.001\right)$. RTCs involving pedestrians and motorcycles had a positive correlation with increased ISS $\left(\mathrm{X}^{2}=14.76 ; \mathrm{p}=0.020\right)$.

Admission pattern and treatment modalities

A total of $78(65 \%)$ patients were admitted to the surgical wards, $32(26.7 \%)$ were treated and discharged home from the A \& E department while $10(8.3 \%)$ needed intensive care unit (ICU) admission. Majority of the injuries (95, 55.9\%) were treated surgically while $75(44.1 \%)$ injuries were treated non-operatively. Wound debridement and wound closure were the most frequently performed procedures followed by manipulation under anaesthesia and application of plaster of Paris (POP) for simple fractures. The number of surgical procedures performed are as follows: craniotomy 10 , external fixation 6 , internal fixation 8 , exploratory laparotomy 5 , tube thoracostomy 4 , wound debridement and closure 55, split skin grafting 5 and flap cover 2 .

\section{Outcome of treatment}

The duration of hospitalization ranged between 1-63 days with a mean duration of $10.4 \pm 5.8$ days. Injuries resulting from RTCs and severe injuries with increased ISS were associated with significantly longer duration of hospitalization $\left(X^{2}=26.12 ; p=0.001\right)$. Four $(3.3 \%)$ patients left against medical advice on account of financial difficulty and $9(7.5 \%)$ were referred to other facilities on request, on account of proximity to the family. After a follow-up period of one year, most of the children $(81 ; 67.5 \%)$ had full recovery from the injuries while $19(15.8 \%)$ had residual disabilities such as limb loss or paralysis. A total of 7 patients died, giving a mortality rate of $5.8 \%$. Four patients died from traumatic brain injury while one patient each died from severe flame burns, blunt abdominal injury and blunt chest injury. 
Table 3: Distribution of the place of injury

\begin{tabular}{lll}
\hline Place of injury & Number & $(\%)$ \\
\hline Home & 26 & 21.7 \\
Roadside/street & 42 & 35.0 \\
School & 28 & 23.3 \\
Playground & 14 & 11.7 \\
Factory/industry & 3 & 2.5 \\
Others & 7 & 5.8 \\
\hline Total & 120 & 100 \\
\hline
\end{tabular}

Table 4: Distribution of type of injuries sustained by the patients

\begin{tabular}{lll}
\hline Type of injury & Number & Percent (\%) \\
\hline Traumatic brain injury & 23 & 13.5 \\
Fracture & 46 & 27.1 \\
Dislocation & 7 & 4.1 \\
Bruise/Laceration/Abrasion & 47 & 27.6 \\
Blunt chest injury & 9 & 5.3 \\
Blunt abdominal injury & 16 & 9.4 \\
Burns & 10 & 5.9 \\
Spine injury & 7 & 4.1 \\
Crush injury & 3 & 1.8 \\
Perineal injury & 2 & 1.2 \\
\hline Total & 170 & 100 \\
\hline
\end{tabular}

Table 5: Body region affected by injury

\begin{tabular}{lrc}
\hline & Frequency & Percent (\%) \\
\hline Head and neck & 28 & 16.5 \\
Abdomen & 26 & 15.3 \\
Upper extremity & 41 & 24.1 \\
Lower extremity & 47 & 10.0 \\
Chest & 17 & 4.1 \\
Spine & 2 & 1.2 \\
Serineum & 2 & 100.0 \\
Pelvis & 170 & 100 \\
\hline Total & & \\
\hline
\end{tabular}

\section{Discussion}

The prevalence of paediatric injuries in our study was $10.1 \%$. This is similar to findings from other hospital-based studies in western and northern parts of Nigeria ${ }^{18,19}$. These figures may be much higher because in Nigeria and other developing countries, many injured patients are not treated in hospitals but by non-orthodox practitioners, leading to underreporting and misrepresentation of the true injury burden in our environment ${ }^{20,21}$.

In this study, adolescents (12-17 years) and school age (6-11 years) children accounted for more than half of the children presenting with injuries. This is similar to other studies done in other parts of the world $\mathrm{d}^{22,23}$. The closer attention given to infants and younger children by parents and relatives may be protecting them from sustaining injuries. Additionally, it may be connected with their entry into school with increased exposure to road traffic accidents on their way to school and back home and playground injuries while playing at school.
Males were more affected than females. This is in support of the widely held gender theory that suggests gender differences in socialization. It is believed that socialization process leads males to engage in more risky behaviors than females $^{24}$. The higher levels of activity and likelihood to explore his environment may in turn put male child at higher risk of injuries and resultant mortality compared to females ${ }^{24}$.

The rate of intentional injuries in our study was 10.8\%. This represents an increase from the $2 \%$ reported by AbdurRahman et al. ${ }^{21}$ in a prospective population-based study in 2012, and 5.1\% reported by Hyginus et al. ${ }^{11}$ in a retrospective hospital-based study in 2015. In our setting, many cases of sexual assault and domestic violence against children do not usually present to hospitals for treatment due to social stigmatization and fear of legal prosecution. However, there has been on-going media awareness campaigns against such offences which may have resulted in the increasing reportage of these offences.

RTCs and falls from a height were the most frequent causes of injuries among children dwelling in developing countries with myriad problems of vehicular land transportation $11,18,19,21,23,25$. This is not unexpected as RTIs continue to rise and become a major contributor of morbidity and mortality worldwide. The highest number of RTCs in this study was recorded among children who were pedestrians. This may be due to the fact that many roads in this locality do not have designated pedestrian walk paths and pedestrians are forced to walk on roadsides. Furthermore, lack of designated pedestrian crossing areas and footbridges particularly on 
roads leading to schools and other event centres could expose children and caregivers to danger as they cross roads. Falls accounted for $27.5 \%$ of injuries in our study and was most common among preschool children (4-5 years). Most of the falls happened while the children were playing at home. Public enlightenment programs about the need for more parental supervision of children at home will help to reduce the incidence of falls in our environment.

In contrast to our findings, a study in Kenya reported burn injuries as the most frequent cause of childhood injuries ${ }^{26}$. This was due to the methods of cooking in Kenya and the exposure of children to hot fluids and food. The high incidence of road traffic accidents in our study may be due to reckless driving, over speeding and non-compliance to traffic laws observed amongst many drivers in our environment. The poor state of disrepair of many roads and vehicles may also be contributory. Enforcement of traffic laws, public education of road users, regular road maintenance and construction of pedestrian bridges and walk paths will help to reduce the incidence of transport-related injuries among children.

Most of the injuries in our study occurred along the road or on the streets. This in contrast to the studies by Simon et al. and Hyginus et al. which reported the home as the commonest place of injury ${ }^{11,22}$. Our study underscores the need for provision of safer road transportation in many developing countries. Many of our patients were school age children and adolescents who were injured while going or returning from school, or while on errands outside the home. Other common places of injury in our study were school and home. There is need to ensure that the school and home environment are safe for children by providing adequate supervision of children and eliminating crowded environments and unsafe structures at school and home which may endanger the children.

Majority of our patients presented late to hospital. The mean time to presentation to hospital is prolonged and similar to the findings of Ekenze et al. in Owerri South-East Nigeria $^{27}$. The lack of prehospital services in most cities in Nigeria and the widespread patronage of unorthodox and traditional healers in our environment may explain this delay in hospital presentation among our patients ${ }^{28}$. In addition, Poor health seeking behaviour occasioned by ignorance, financial constraints, out-of-pocket health financing due to poor coverage of national health insurance may also fuel late presentation to hospital.

In agreement with previous studies ${ }^{22,28}$, this study also noted that soft tissue injuries such as lacerations, bruises and abrasions were the most common types of injury sustained by children. With respect to the body region affected by injury, we noted that musculoskeletal injuries affecting mainly the lower extremities were the most common. This is similar to reports by other studies ${ }^{21,28}$. This finding may be attributable to the large number of pedestrian and motorcycle injuries in our study. RTCs involving the use of motorcycles or pedestrians have been associated with high risk of limb injuries because the victims are unprotected ${ }^{2}$. In contrast to other studies that reported that the head was the predominant site of injury in children ${ }^{22,23,26}$, in this study, the head ranked $3^{\text {rd }}$ among the body regions affected by injury. The higher incidence of head injuries in these studies was attributed to the larger head to body ratio in children and the weak neck musculature which put them at risk of head injury even at low velocity injuries ${ }^{30}$. The predominant involvement of older children and adolescents who have smaller head to body ratio and stronger neck musculature in this study may explain the lower incidence of head injuries in this present study.

ISS was used to assess the severity of the injuries. Majority $(62.7 \%)$ sustained minor injuries. Cumulatively, most of the injuries in our study occurred either at home, at school or at the playground which are predominantly low energy injuries. Other studies have also reported the predominance of minor injuries among children ${ }^{22,31}$. Higher ISS was associated with pedestrian and motorcycle-related injuries and patients with limb injuries. These are patients who are more likely to sustain more severe injuries from high energy injuries. Patients with higher ISS presented earlier to hospital and had a significantly longer hospital stay. The more severely injured patients are more likely to seek hospital care earlier than those with minor injuries, and the more severe injuries will need a longer hospitalization.

Most of our patients were treated surgically with wound debridement as the most frequently performed surgical procedure. The modality of treatment and procedures performed reflect the pattern of injuries sustained by the patients. There was a high incidence of injuries requiring surgical intervention which may explain the high incidence of surgical treatment.

The mean duration of hospitalization in this study was significantly shorter than 52.8 days reported by Hyginus et al. ${ }^{11}$. but comparable to 9.7 days reported by Simon et al. ${ }^{22}$. Majority of our patients sustained minor injuries and needed a short duration of hospitalization. Duration of hospitalization is known to be associated with increased cost of treatment, psychological distress and higher morbidity among trauma patients. We noted that increased duration of hospitalization was related to increased ISS, and injuries resulting from RTCs.

The mortality rate in this study was $5.8 \%$ which is lower than that reported by Simon et al. ${ }^{22}$ but similar to the reports by Hyginus et al. ${ }^{11}$ and Abantanga et al. ${ }^{31}$ The reason for the generally good outcome could be attributable to the injury severity (Injury Severity Score) of our patients since ISS is known to correlate with morbidity and mortality. The study recorded a low mean ISS of $6.4 \pm 2.8$ as low ISS (below 15) is generally known to be associated with an improved patient outcome.

A major limitation of this study was single-site hospital-based study with a possible selection bias. Many childhood injuries may not present to our hospital, though a referral hospital, but rather treated at home or by traditional bonesetters. Thus, the true burden of childhood injuries in our setting may not be reflected in this study. Despite these limitations, the study helps to describe the pattern and epidemiology of childhood injuries in our setting, highlighting the possible areas for intervention to reduce the consequences of childhood injuries to the barest in developing nations like ours.

\section{Conclusion/Recommendation}

Childhood injuries are common and predominantly affect male children. Road traffic accidents and falls were the leading causes of paediatric injuries. The roadside/street, school and home were common places where these injuries occurred. The most common type of injuries were soft tissue injuries such as bruises, abrasions and lacerations, 
and fractures. It is recommended that road transportation be made safer for children by the provision of pedestrian crossways, foot bridges and education of road users. Safer school and home environments and greater supervision of children will help to reduce the burden of childhood injuries and the consequent morbidity and mortality being tackled by the healthcare workers.

\section{References}

1. Shackford SR, Mackersie RC, Holbrook TL, Davis JW, HollingsworthFridlund P, Hoyt DB, et al. The epidemiology of traumatic death. A population-based analysis. Arch Surg 1993; 128: 571-5.

2. Sauaia A, Moore FA, Moore EE, Moser KS, Brennan R, Read RA, et al. Epidemiology of trauma deaths. A reassessment. J Trauma 1995; 38: $185-93$.

3. World Health Organization. Child and adolescent injury prevention: A global call to action. Geneva, Switzerland: World Health Organization; 2005. https://apps.who.int/iris/handle/10665/43279 (Accessed 2nd May 2019).

4. Deen JL, Vos T, Huttley SRA. Injuries and non-communicable diseases: emerging health problems of children in developing countries Bull World Health Organ 1999; 17: 518-524.

5. Peden M, Oyegbite K, Ozanne-Smith J, Hyder A, Branche C, Rahman F, et al. World Report on Child Injury Prevention. Geneva: WHO; 2008. P. 1-7.

6. Solagberu BA, Adekanye AO, Ofoegbu CP, Udoffa US, AbdurRahman LO, Taiwo JO, et al. Epidemiology of trauma deaths. West Afr J Med 2003; 22: 177-81.

7. Oyedeji GA, Oyedeji AO. Causes, pattern and outcomes of severe injuries in children. A hospital-based study. Niger J Paediatr 2003; 30: 86-92.

8. UNICEF: A league table of child deaths by injury in rich nations. Innocenti Report Card No 2, February 2001. UNICEF Innocenti Research Centre, Florence, Italy. Inj Prev 2001; 7:166-7.

9. Chapp-Jumbo AU, Adisa AC. Pattern of trauma among paediatric in-patients- The Abia state university teaching hospital experience. Eur J Sci Res. 2009; 29:411.

10. Abantanga FA, Mock CN. Paediatric trauma: Epidemiology, prevention and control. In: Ameh EA, Bickler SW, Lakhoo K, Nwomeh BC, Poenaru D, editors. Paediatric Surgery: A Comprehensive Text for Africa. Seattle: Global Help Organization; 2012.157-63.

11. Hyginus EO, Okechukwu UJ, Victor IM, Christian OC, Anthony U. Epidemiology of admitted cases of childhood injuries in Nnamdi Azikiwe University Teaching Hospital Nnewi, Nigeria. Ann Trop Med Public Health. 2015;8:272-5.

12. Macarthur C, Hu X, Wesson DE, Parkin PC. Risk factors for severe injuries associated with falls from playground equipment. Acc Anal Prev. 2000; 32:377-382.

13. Afukaar FK, Antwi P, Ofosu-Amaah S. Pattern of road traffic injuries in Ghana: Implications for control. Inj Contol Saf Promo 2003; 10:69-76.

14. Harvey A, Towner E, Peden M, Soori H, Bartholomeos K. Injury prevention and the attainment of child and adolescent health. Bull World Health Organ. 2009; 87:390-394.

15. Orton E, Kendrick D, West J, Tata LJ. Independent risk factors for injury in pre-school children: Three population based nested casecontrol studies using routine primary care data. PLoS One 2012; 7:e35193.

16. Nassir AA, Bello JO, Ofoegbu CK, Abdur-Rahman LO, Yakub S, Solagberu BA. Childhood motorcycle-related injuries in a Nigerian city - prevalence, spectrum and strategies for control. S Afr J Child Health 2011;5:48-9.

17. Bolorunduro OB, Villegas C, Oyetunji TA, Haut ER, Stevens KA, Chang DC, et al. Validating the Injury Severity Score (ISS) in different populations: ISS predicts mortality better among Hispanics and females. J Surg Res. 2011; 166 (1):):40--44.

18. Adesunkanmi AR, Oginni LM, Oyelami AO, Badru OS. Epidemiology of childhood injury. J Trauma 1998; 44:506-512.

19. Abubakar S, Ahmed A, Farouk Z, Gadanya M, Jimoh ML. Prevalence and pattern of unintentional domestic accidents and trauma amongst children attending public hospitals in Kano, Nigeria. Sahel Med J 2018; 21:6-12.

20. Onyemaechi NO, Lasebikan OA, Elachi IC, Popoola SO, Oluwadiya KS. Patronage of traditional bonesetters in Makurdi, north-central Nigeria. Patient Preference and Adherence 2015:9 275-279.

21. Abdur-Rahman LO, Taiwo JO, Ofoegbu CK, Adekanye AO, Ajide OO, Ijagbemi CY, et al. Community survey of childhood injuries in North-Central Nigeria. Ann Pediatr Surg 2015; 11:136-139.

22. Simon R, Gilyoma JM, Dass RM, Mchembe MD, Chalya PL. Paediatric injuries at Bugando Medical Centre in Northwestern Tanzania: a prospective review of 150 cases. J Trauma Manag Outcomes $20137: 10$

23. Karbakhsh M, Zargar M, Zarei MR, Khaji A. Childhood injuries in Tehran: a review of 1281 cases. Turkish J Paed 2008, 50:317-325.

24. Britton J. Preventing fall injuries in children. Wis Med J. 2005; $1: 33-36$.

25. Simmons D. Accidents in Malawi. Arch Dis Child. 1985; 60(1): 64-66.

26. Gome DL, Mutiso VM, Kimende K. Paediatric trauma at KNH, Nairobi Kenya. East Centr Afr. J Surg 2005; 10(2):33-36.

27. Ekenze SO, Anyanwu KK, Chukwumam DO. Childhood trauma in Owerri (south east) Nigeria. Niger J Med 2009; 18(1): 79-83.

28. Onyemaechi NO, Nwankwo OE, Ezeadawi RA. Epidemiology of injuries seen in a Nigerian tertiary hospital. Niger J Clin Pract 2018; 21(6): 752-757.

29. Osmond MH, Brennan-Barnes M, Shephard AL. A 4-year review of severe pediatric trauma in eastern Ontario: a descriptive analysis. J Trauma 2002; 52:8-12.

30. Al Kilani HHY, Al Mosheh AW, Khalid MK, Tawil MS, Ibrahim TK. Paediatric trauma: a hospital based study of pattern of childhood injuries in the State of Qatar. Middle East J Emerg Med 2001, 1(1):1822.

31. Abantanga FA, Mock CN. Childhood injuries in an urban area of Ghana A hospital-based study of 677 cases. Pediatr Surg Int 1998; 13: 515-518. 